\title{
Application of process tomography in gas-solid fluidised beds in different scales and structures
}

DOI:

10.1088/1361-6501/aaa509

\section{Document Version}

Accepted author manuscript

Link to publication record in Manchester Research Explorer

\section{Citation for published version (APA):}

Wang, H. G., Che, H. Q., Ye, J. M., Tu, Q. Y., Wu, Z. P., Yang, W. Q., \& Ocone, R. (2018). Application of process tomography in gas-solid fluidised beds in different scales and structures. Measurement Science and Technology, 29(4), [044001]. https://doi.org/10.1088/1361-6501/aaa509

\section{Published in:}

Measurement Science and Technology

\section{Citing this paper}

Please note that where the full-text provided on Manchester Research Explorer is the Author Accepted Manuscript or Proof version this may differ from the final Published version. If citing, it is advised that you check and use the publisher's definitive version.

\section{General rights}

Copyright and moral rights for the publications made accessible in the Research Explorer are retained by the authors and/or other copyright owners and it is a condition of accessing publications that users recognise and abide by the legal requirements associated with these rights.

\section{Takedown policy}

If you believe that this document breaches copyright please refer to the University of Manchester's Takedown Procedures [http://man.ac.uk/04Y6Bo] or contact uml.scholarlycommunications@manchester.ac.uk providing relevant details, so we can investigate your claim.

\section{OPEN ACCESS}




\title{
Application of process tomography in gas-solids fluidised beds in different scales and structures*
}

\author{
H.G. Wang ${ }^{1,2}$, H.Q. Che ${ }^{1,2}$, J. M. Ye ${ }^{1}$, Q.Y. Tu ${ }^{1}$, Z.P. Wu ${ }^{3}$, W.Q. Yang ${ }^{3}$ and R. Ocone ${ }^{4}$ \\ 1. Institute of Engineering Thermophysics, Chinese Academy of Sciences, Beijing 100190, China \\ 2. University of Chinese Academy of Sciences, Beijing 100190, China \\ 3. School of Electrical and Electronic Engineering, University of Manchester, Sackville Street, M13 9PL, UK \\ 4. School of Engineering and Physical Sciences, Heriot-Watt University, Edinburgh EH14 4AS, UK
}

\begin{abstract}
Gas-solids fluidised beds are commonly used in particle-related processes, e.g. for coal combustion and gasification in the power industry, and coating and granulation process in the pharmaceutical industry. Because the operation efficiency depends on the gas-solids flow characteristics, it is necessary to investigate the flow behaviour. This paper is about application of process tomography, including electrical capacitance tomography (ECT) and microwave tomography (MWT), in multi-scale gas-solids fluidisation processes in the pharmaceutical and power industries. This is the first time that both ECT and MWT are applied for this purpose with multi-scales and complex structure. To evaluate the sensor design and image reconstruction and to investigate the effects of sensor structure and dimension on the image quality, a normalised sensitivity coefficient is introduced. In the meanwhile, computational fluid dynamic (CFD) analysis based on a computational particle fluid dynamic (CPFD) model and a two-phase fluid model (TFM) is used. Part of the CPFD-TFM simulation results are compared and validated by experimental results from ECT and/or MWT. By both simulation and experiment, the complex flow hydrodynamic behaviour in different scales is analysed. Time-series capacitance data are analysed both in time and frequency domains to reveal the flow characteristics.
\end{abstract}

Keywords: Process tomography, Fluidised bed, Electrical capacitance tomography, Microwave tomography, Sensitivity analysis

\section{Introduction}

Gas-solids fluidised beds are commonly used for coal combustion and gasification in the power industry (Wang and Yang 2011), and coating and granulation process in the pharmaceutical industry (Wang et al. 2016). The operation efficiency depends on the operation parameter settings and the gas-solids mixing characteristics (Koornneef et al. 2007). For a coal combustion process in a fluidised bed, it is important to keep homogeneous solids distribution in the dense zone in the fluidised bed riser to achieve high combustion efficiency, in particular for a large circulating fluidised bed (CFB) with complex geometrical combustion chamber and multi-cyclone separators. In addition, for a CFB boiler with complex geometry, it is important to control the solids distribution in the dense zone in the chamber to balance the heat and mass transfer during the coal combustion process. However, due to the complex gas-solids two-phase flow and multi-scales, it is difficult to measure the processes and difficult to diagnose the processes using the conventional measurement tools, using single point measurement, such as pressure and optical fibre probes (Werther 1999, Truton 2008, Ge et al. 2014). Therefore, it is necessary to develop non-intrusive and non-invasive techniques and obtain cross-sectional information for optimisation and control of the process (van Ommen et al. 2008).

Process tomography can provide useful information for process monitoring and fault diagnosis of gas-solids fluidised beds. Compared with other process tomography techniques and considering the non-conductive nature of the solids in most gas-solids fluidised beds used in the power and pharmaceutical industries, electrical capacitance tomography (ECT) is the most suitable for measuring the fluidisation processes (Yang and Peng 2003, Wang et al. 2010 and 2012, Zhang et al. 2014, Sun and Yang 2016). For scaling up a fluidised bed process from the lab scale to the production scale with different riser structures, ECT can provide additional information on the gas-solids flow hydrodynamic characteristics, i.e. flow regime transition from bubbling to slugging flow (Qiu et al. 2015). Pharmaceutical fluidised beds have been investigated in different scales: labscale, pilot-scale and production-scale by ECT (Wang and Yang 2011). Recently, ECT is combined with microwave tomography (MWT) to carry out static tests of wet-granules processes (Wang et al. 2016). One of the tasks is to design sensors for the specific process (Yang 2010) with consideration of temperature, pressure

*Correspondence author, Tel.: 0086-10-82543140, E-mail: wanghaigang@iet.cn (H.G. Wang) 
and dynamic range. For investigation of gas-solids fluidised beds of different dimensions and structures, process tomography sensors must be specifically designed and optimised to achieve high quality images.

The aims of this work are to apply process tomography including ECT and MWT in fluidised beds with different scales and structure, to provide online monitoring and fault diagnosis, and to develop a new approach to scaling up the fluidisation process. ECT and MWT sensors in different scales are designed and combined together as dual-modality tomography to measure the permittivity and conductivity distributions. In the following, key issues will be discussed, including the sensor design and optimisation, image reconstruction with a large scale chamber, measurement strategy and mutual validation between process tomography and CFD simulation. To evaluate the signal and reconstructed images, parameters including signal-to-noise ratio (SNR) and normalised sensitivity coefficient are introduced. To reveal the flow characteristics, time-series capacitance data are analysed both in time and frequency domains.

\section{Sensor design and image reconstruction}

\subsection{ECT sensor design with different dimension and structure}

For gas-solids fluidised beds used in the powder and pharmaceutical industries, the dimension of the process chamber changes dramatically from centre meters to meters (Wang et al. 2011), and the chamber has different structure, e.g. circular, square and rectangular (Liu et al. 2002, Cao et al. 2010). Tomography sensors are described in literatures (Pugsley et al. 2003, Makkawi and Wright 2004, Wang et al. 2012). Application of ECT and MWT in an industry process involves optimisation of sensor design to achieve high quality images. Figure 1 shows three fluidised beds with different scales, i.e. lab-scale, pilot-scale and production-scale. The dimensions and shape of the chambers of the three fluidised beds are given in Table 1.

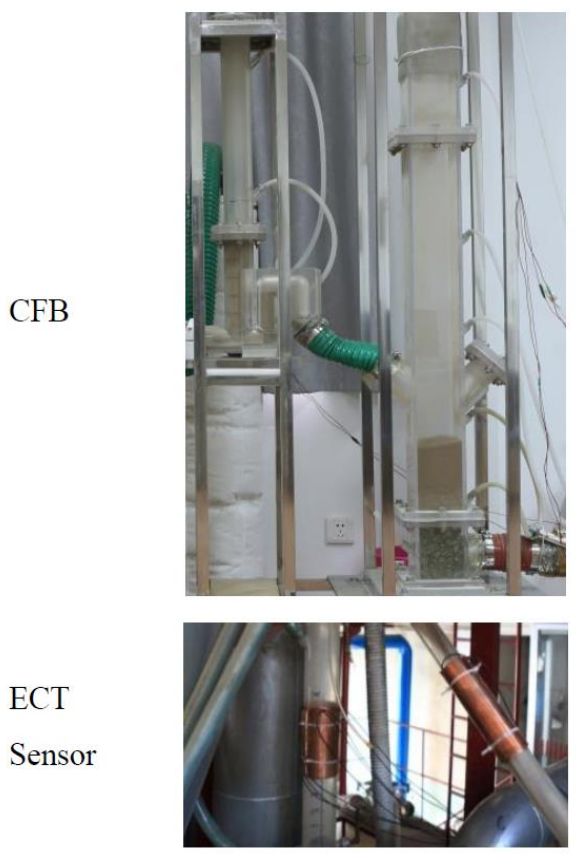

(a) Lab-scale
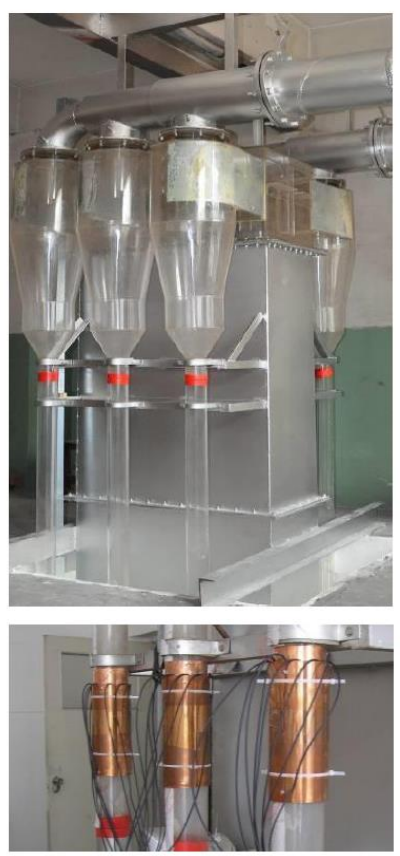

(b) Pilot-scale
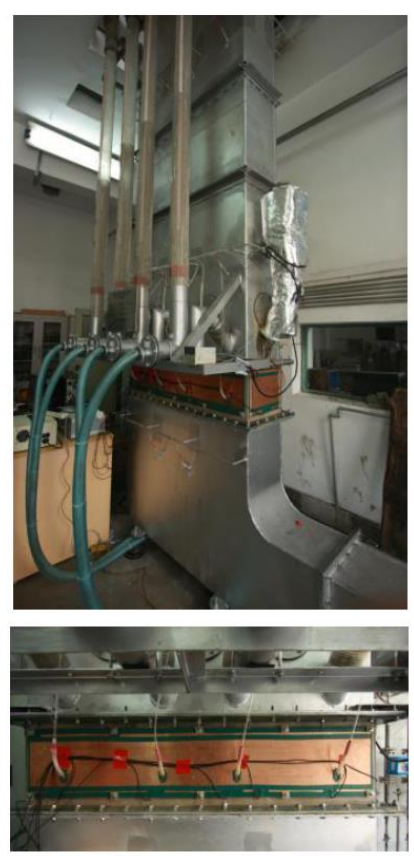

(c) Production-scale

Figure 1 Fluidised beds in different scales

Table 1 Dimensions of fluidised beds in different scales

\begin{tabular}{llll}
\hline Fluidised bed & Height $(\mathrm{m})$ & Cross section $(\mathrm{cm})$ & Riser shape \\
\hline Lab-scale & 1.5 & $14 \times 14$ & Square \\
Pilot-scale & 4 & $40 \times 60$ & Rectangular \\
Production-scale & 6 & $120 \times 40$ & Circular \\
\hline
\end{tabular}

Figure 2 shows ECT sensors designed for the above fluidised beds with different dimension and structure. In these structures, the circular and rectangular sensors shown in Figure 2 (a) and (b) are common in gas-solids fluidised beds in the power industry. The rectangular sensor shown in Figure 2 (c) is one typical structure used 
in power plant for coal combustion. It has 12 electrodes in total, 4 electrodes along each long side and 2 electrodes in each short side. The overall size of the sensor is $120 \mathrm{~cm} \times 32 \mathrm{~cm}$. The sensor shown in Figure 2 (d) with 12-4-8 combined electrodes (i.e. 12 external electrodes, 8 internal electrodes and 4 middle electrodes) is used for coating and granulation in a pharmaceutical fluidised bed.

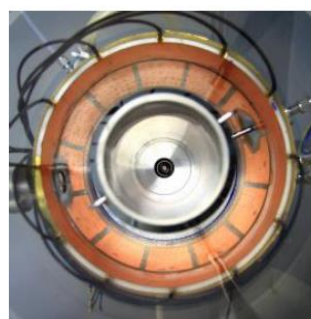

(a) Circular

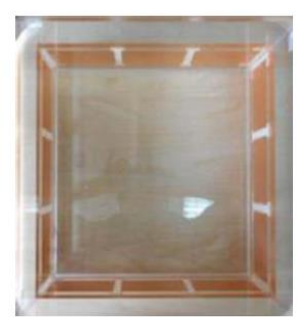

(b) Square

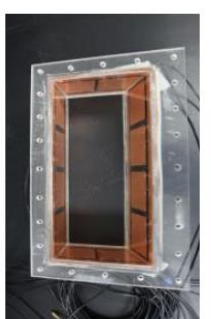

(c) Rectangular

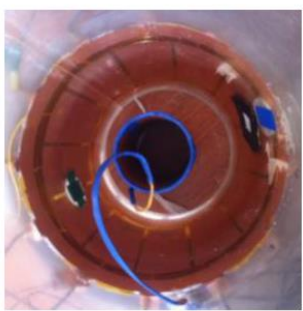

(d) Combined

Figure 2 ECT sensors with different structures

\subsection{ECT image reconstruction}

With ECT, a gas-solids flow in a fluidised bed is interrogated by electrodes from different viewing angles around a cross section. For a typical ECT sensor with 12 electrodes as shown in Fig. 2 (a), (b) and (c), 66 independent capacitance measurements are obtained between pairs of electrodes. With the sensing area being divided into many pixels, e.g. $64 \times 64$ pixels, an image representing the cross-sectional distribution of solids is reconstructed using image reconstruction algorithms.

Image reconstruction for ECT is a non-linear ill-posed inverse problem (Yang et al. 1999, Yang and Peng 2003). Often, the inverse problem of ECT is simplified to a linear system and iteration procedure is used to improve the image quality (Liu et al. 2002). In the literature, a number of algorithms have been reported for reconstructing the solids distribution in fluidised beds. Table 2 summaries typical algorithms used. It can be seen that the linear back-projection (LBP) (Xie et al. 1992) and Landweber iteration (Yang et al. 1999) are the two most popular algorithms used in gas-solids fluidised beds (Liu et al. 2004, Liu et al. 2005, Wang and Yang 2010, Wang and Yang 2011). LBP is fast but performs poorly for complicated distributions, such as "crown-like" shape solids distribution in a fluidised bed (Pain et al. 2001). In such conditions, Landweber iteration is more powerful to reconstruct the complicated distribution than LBP (Liu et al. 2002, Wang et al. 2008). Therefore, the Landweber iteration algorithm is used to reconstruct solids distribution and identify the flow regime in gassolids fluidised beds.

Table 2 Image reconstruction for gas-solids fluidised beds

\begin{tabular}{|c|c|c|}
\hline Authors & ECT sensors & Image reconstruction algorithm \\
\hline Dyakowski et al. (2000) & Circular, 8 electrodes & Landweber iteration \\
\hline Liu et al. $(2002,2005)$ & Rectangular, 12 electrodes & $\begin{array}{l}\text { Landweber iteration with optimized iteration step } \\
\text { length }\end{array}$ \\
\hline Marashdeh et al. (2006) & Circular, 12 electrodes & Non-linear Neural network based iteration \\
\hline Wang et al. (2008) & Rectangular, 12 electrodes & Landweber iteration with optimized step length \\
\hline Banaei et al. (2015) & Circular, 12 electrodes & Landweber iteration and Tikhonov iteration \\
\hline Chandrasekera et al. (2015) & Circular, 12 electrodes & $\begin{array}{l}\text { Total variation iterative soft thresholding } \\
\text { algorithm }\end{array}$ \\
\hline Zhao et al. (2016) & Circular, 12 electrodes & LBP \\
\hline Agu et al. (2017) & Circular, 12 electrodes & LBP \\
\hline Li et al. (2017) & Circular, 8 electrodes & LBP \\
\hline
\end{tabular}

The Landweber iteration is written as (Yang et al. 1999)

$$
\begin{gathered}
\mathrm{G}^{0}=\mathrm{S}^{\mathrm{T}} \cdot \mathrm{C}_{\mathrm{N}} \\
\mathrm{G}^{\mathrm{I}+1}=\mathrm{G}^{\mathrm{I}}+\alpha \cdot\left(\mathrm{C}_{\mathrm{N}}-\mathrm{S} \cdot \mathrm{G}^{\mathrm{I}}\right)
\end{gathered}
$$


where, $\mathrm{C}_{\mathrm{N}}$ is the normalised capacitance vector, $\mathrm{S}$ is an $m \times \mathrm{n}$ sensitivity matrix, $\mathrm{S}^{\mathrm{T}}$ is the transpose of $\mathrm{S}, \mathrm{m}$ is the pixels number in the sensing area and $\mathrm{n}$ is the number of capacitance, $\mathrm{G}$ is the grey level, $\mathrm{I}$ is the iteration number, and $\alpha$ is the relaxation factor.

A first image is reconstructed by LBP. Then each subsequent image, $\mathrm{G}^{\mathrm{I}+1}$, is obtained from the previous image, $\mathrm{G}^{\mathrm{I}}$, with an added correction term plus the step length of $\alpha$ by equation (2). The value of $\alpha$ is often chosen between 1 and 2 empirically. In this research, an optimum method is used to calculate the step length (Liu et al. 2004)

$$
\alpha=\frac{\left\|S^{\mathrm{T}}\left(\mathrm{C}-\mathrm{SG}^{\mathrm{I}}\right)\right\|_{2}^{2}}{\left\|\mathrm{SS}^{\mathrm{T}}\left(\mathrm{C}-\mathrm{SG}^{\mathrm{I}}\right)\right\|_{2}^{2}}
$$

With the optimal step length, the number of iterations can be reduced for a reliably converged result. In equations (1) and (2), the normalised capacitance is obtained by

$$
C_{N}=\frac{C_{M}-C_{L}}{C_{H}-C_{L}}
$$

where $\mathrm{C}_{\mathrm{M}}$ is the measured capacitance, $\mathbf{C}_{\mathrm{L}}$ is the capacitance when an ECT sensor is empty and $\mathbf{C}_{\mathrm{H}}$ is the capacitance when the sensor is filled with solids. The validation of image errors has been given in references (Wang et al. 2016).

Based on the reconstructed permittivity distribution, the average solids concentration in the cross section is linearly related to the grey level of ECT image by (Ge et al. 2016)

$$
\beta=\vartheta \cdot \frac{\sum_{i=1}^{m} G_{i}(x, y) \cdot a_{i}(x, y)}{\sum_{i=1}^{m} a_{i}(x, y)}
$$

where $\vartheta$ is the packing factor, a is the area of pixel in the cross-sectional area. The value of $\vartheta$ is estimated to be 0.62 when the diameter ratio of the vessel to the particle is higher than 10 (Fayed and Otten 2013).

\subsection{MWT sensor design and image reconstruction algorithm}

Similar to ECT, MWT has been developed for more than two decades, but mainly for medical applications (Franchois and Pichot 1997, Xu et al., 2014). Recently, MWT has been developed for multiphase flow measurement (Wu et al. 2009, Wang et al., 2016). Compared with ECT, MWT has a wide frequency range $(1.0 \sim 2.5 \mathrm{GHz})$ and can be used to measure materials with high permittivity and conductivity, which are common in the coating and granulation process in pharmaceutical fluidised beds (Wang et al., 2016). Figure 3 shows circular and square MWT sensors used in gas-solids fluidised beds with particles of high moisture content. Both sensors have 16 symmetrically arranged antennas and the data acquisition system has 16 measurement channels. The sampling rate is 31 frames per second.

Compared with ECT, image reconstruction for MWT is servery nonlinear and more complicated due to the scattering effect (Wu et al. 2015). A number of iteration algorithms have been developed for MWT, including Gauss-Newton method (Frachois and Pichot 1997), Newton-Kantorovich method (Roger 1981 and Jochimowicz et al. 1991), quasi-Newton method (Franchois and Tijhuis 2003), conjugate gradient method (Harada et al. 1995 and Lobel et al. 1996) and sequential quadratic programming method (Hu et al. 2005). In this research, an improved Newton-Kantorovich is used to solve the nonlinear and ill-posed inverse problem (Wu and Wang 
2017). The solution is first determined by solving a Newton equation, which is a linearised approximation of the MWT inverse problem. The details of the iterative algorithm are given in references (Semenov et al. 2005, Wu et al. 2009, Wang et al. 2016).

MWT sensor

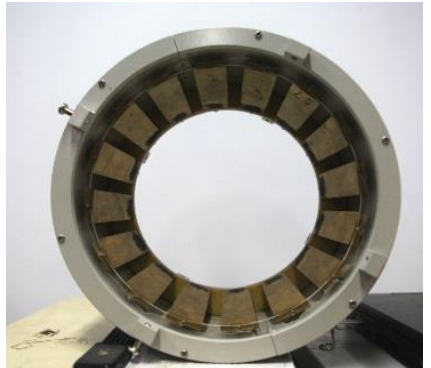

MWT image

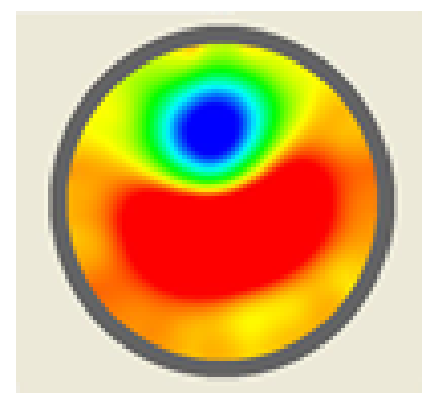

(a) Circular
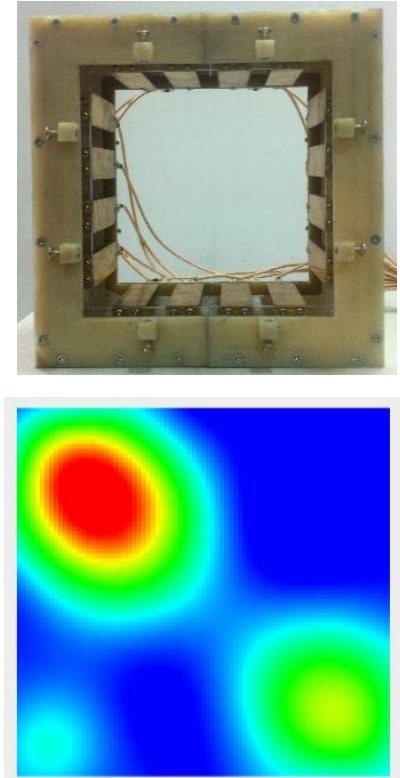

(b) Square

Figure 3 Microwave tomography sensors in different shape

\subsection{Measurement procedure of ECT and MWT}

In this research, an AC-ECT system from the ECT Instruments Ltd, UK is used, which consists of a control box with 16 measurement channels. The excitation frequency can be programmed in the range of $10 \mathrm{kHz}$ to $500 \mathrm{kHz}$ and the voltage amplitude up to $20 \mathrm{~V}_{\mathrm{p}-\mathrm{p}}$. The excitation frequency and voltage can be programmed. For each setting, low and high calibration data are saved and used to evaluate the signal-to-noise ratio (SNR) as well as image errors with different ECT sensors. Based on the above procedure, the optimised frequency and voltage can be identified for a specific ECT sensor. The MWT system is developed by Sensona Ltd, UK with 16 symmetrically arranged antennas, 16 measurement channels and Sensosoft image reconstruction software. The excitation frequency of MWT system can be set in a range from $1.0 \mathrm{GHz}$ to $2.5 \mathrm{GHz}$.

\section{Application of ECT/MWT in gas-solids fluidised beds}

\subsection{ECT result analysis for different-scale fluidised beds}

Figures 4 to 8 show the measurement results with three different fluidised beds using the ECT sensors shown in Figure 2 and comparison of the measurement results with CFD simulation. All images are reconstructed by Landweber iteration with 10 iterations. The CFD simulation uses a two-fluid model (TFM), which are based on the kinetic theory for granular flows (Lun et al. 1984, Ding and Gidaspow 1990). In this approach, the usual thermo-dynamic temperature is replaced by the granular flow temperature. The viscosity, stress and pressure of solids are a function of the granular temperature, which varies with time and position in a fluidised bed. The detailed information of the TFM model is given in references (Wang et al. 2016).

For the lab-scale fluidised bed as shown in Figure 4, it can be seen that air bubbles move randomly in the central region of the chamber. However, for the fluidisation process in the pilot-scale fluidised bed as shown in Figure 5 (b), the gas-solids flow behaviour changes dramatically compared with the lab-scale fluidised bed. In a fluidised bed of pilot-scale, it is difficult to control the gas-solids flow due to a large ratio of width to length. The image shown in Figure 5 (c) indicates that high density particles move on the left and low density particles move on the right of the chamber. This indicates defluidisation, which should be avoided to reduce the chance of hazard.

To investigate the gas-solids flow hydrodynamic characteristics of the pilot-scale fluidised bed in the dense-phase flow regime, four pressure transducers are installed as shown in Figure 5 (a) and the pressure drops are measured 
and compared with ECT results. The data acquisition rate is set as 150 samples per second for the pressure transducer and the data acquisition time is 250 seconds. Figure 6 shows comparison with different fluidisation velocity. The four pressure signals show the flow characteristics with different flow velocity. For the lower value, i.e. $0.3 \mathrm{~m} / \mathrm{s}$ and $0.6 \mathrm{~m} / \mathrm{s}$, the left side of the CFB riser is fully occupied by high solids concentration, which can be identified both by pressure and ECT. The gas-solids flow is in defluidisation in this case and the process is loss balance, which should be avoided in an industrial process (Rüdisüli et al. 2012). For the case of relative high velocity, i.e. $1.4 \mathrm{~m} / \mathrm{s}, 2.8 \mathrm{~m} / \mathrm{s}$ and $3.5 \mathrm{~m} / \mathrm{s}$, the process is in good fluidisation, which is indicated by uniform pressure distribution among the four sensors. The main reason for the defluidisation is improper wind box design under the air distributor. As well known, the performance of the gas distributor often determines the performance of a fluidised bed (Geldart and Baeyens 1985). The measurement result indicates that new wind box should be properly designed, to achieve uniformity primary air distribution. This is the key to maintain the stability of fluidisation with large-scale and high thermal capacity (Depypere et al. 2004, Yan et al. 2017). It can be seen that ECT images provide useful information for control of a gas-solids flow in a CFB chamber with large ratio of width to length.

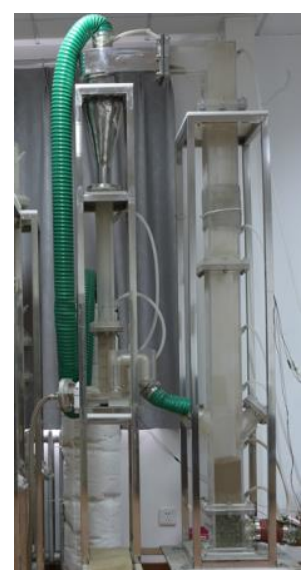

(a) Fluidised bed
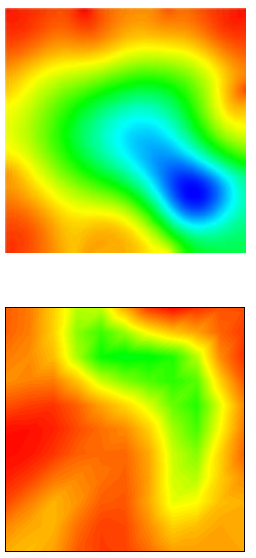

Figure 4 ECT images of lab-scale fluidised bed (scale: $14 \mathrm{~cm}$ )

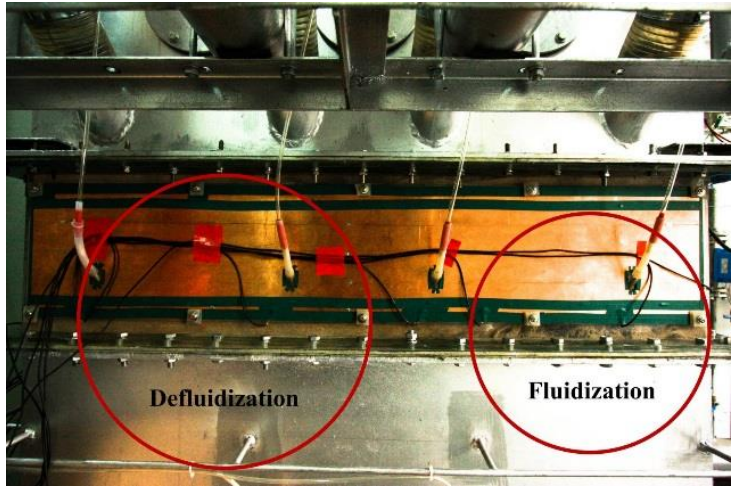

(a) Fluidised bed with ECT sensor
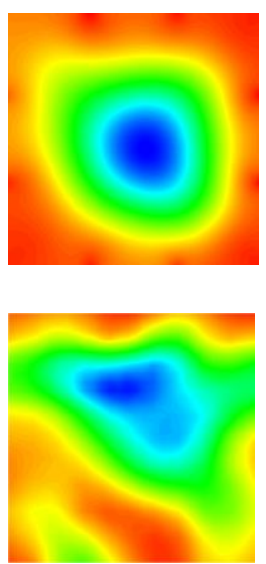

(b) ECT

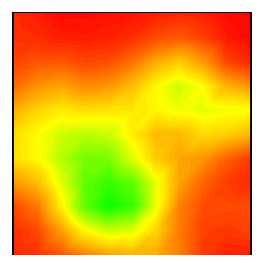

(c) CFD
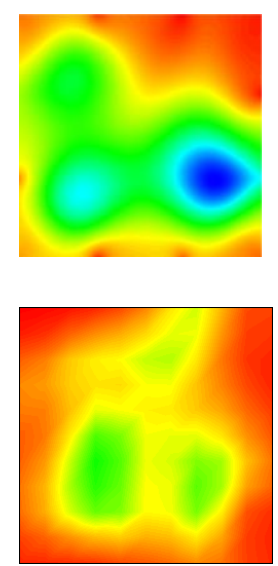

Figure 5 ECT images of pilot-scale fluidised bed (scale: $120 \mathrm{~cm} \mathrm{x} 40 \mathrm{~cm}$ )

Figure 7 shows ECT images of a production-scale gas-solids fluidised bed, MP-4 FlexStream ${ }^{\mathrm{TM}}$, and validation by computational particle fluid dynamic (CPFD) simulation. FlexStream ${ }^{\mathrm{TM}}$ is a multi-purpose processor designed for use in the pharmaceutical industry by the GEA pharmaceutical company in Switzerland. There are three dual-fluid spray nozzles located in the bottom of the bed and used to spray coating solution into the bed. It enables three processes, i.e. granulation, drying and coating, to be carried out in one processor. However, it is difficult to control the process due to the large cross section and the effect of atomised air on the gas-solids fluidised bed. To investigate the complex gas-solids flow characteristics, a large-scale ECT sensor is designed and installed into the bed and CFD simulation is used to validate the measurement results. The CFD models used in this simulation is based on CPFD. This method incorporates the multi-phase-particle-in-cell (MP-PIC) method for calculating a dense gas-solids flow (Andrews 1996, Snider 2001). In CPFD, the gas phase is modelled as a continuous fluid and particles as a discrete phase, which can handle particle size distribution. Particles are classed into numerous of computational parcels. Each parcel represents a number of particles, which have a same velocity and material property in the computational domain. Billions of particles can be 
simulated efficiently. The detailed procedure and equations are given in references (Jiang et al. 2014 and Qiu et al. 2015).

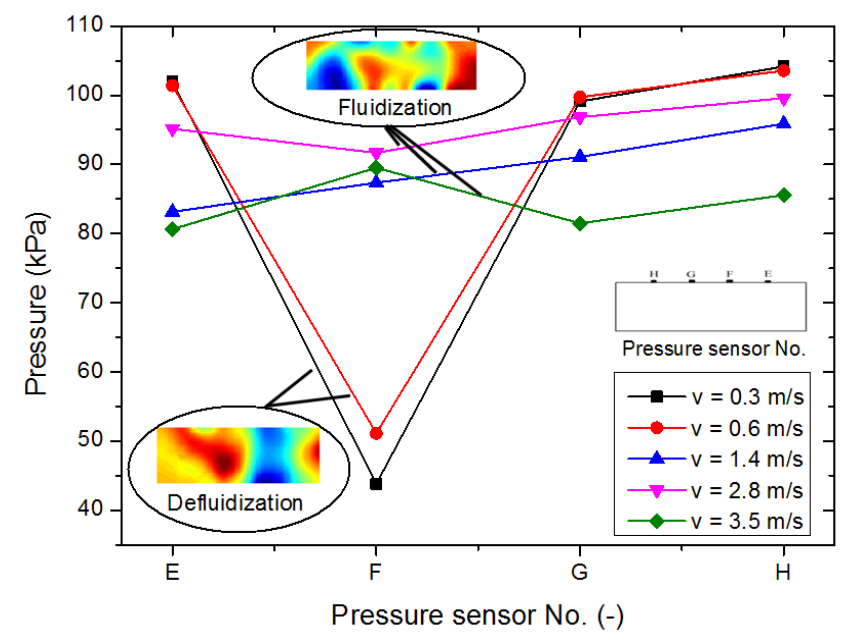

Figure 6 ECT images and pressure measurement for a pilot-scale fluidised bed

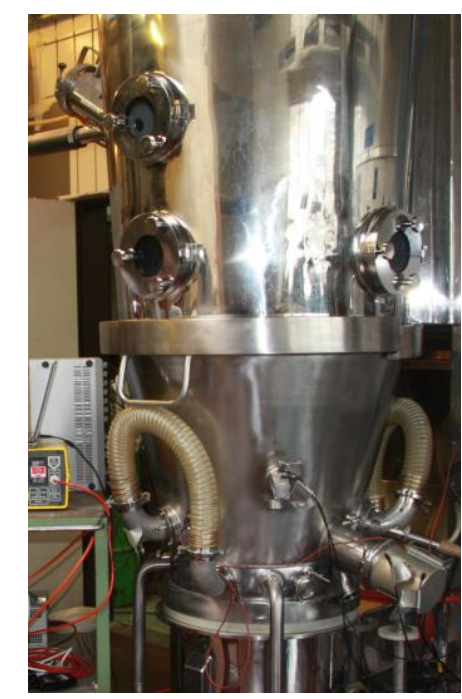

(a)

Production-scale fluidised bed
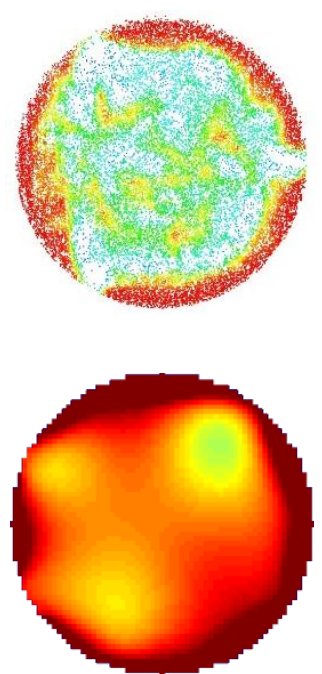

(d)

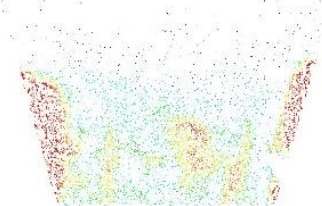

d) $\mathrm{CPFD}$

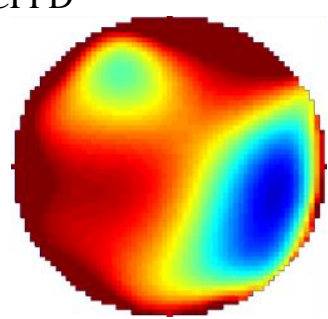

(e) ECT

Figure 7 ECT images with production-scale fluidised bed (scale: $1 \mathrm{~m}$ )

Comparing the images shown in Figures 4 and 7, it is clear that the hydrodynamic behaviour in the production scale fluidised bed is different from that in the lab-scale and pilot-scale fluidised beds. There are more air bubbles moving in the production-scale fluidised bed than in lab-scale and pilot-scale fluidised beds. The flow characteristics are similar to each other in the fluidised beds with three different diameters by $\mathrm{Du}$ et al. (2005). The test results demonstrate that ECT can catch the detailed information in a production-scale fluidised bed, e.g. multiple-bubble movement.

Figure 8 shows the test results with each nozzle switched on in turn, i.e. No. 1 and No. 2 for the production-scale fluidised bed as shown in Figure 7. The capacitance data in Figure 8 came from adjacent electrode pairs: (a) from electrode pairs near nozzle 1; (b) from electrodes pairs near nozzle 2. It is clear that the capacitance reduced after the nozzle located between each electrode pairs switching on respectively. The ECT images clearly show the effect nozzle(s) on the gas-solids process. Due to the spraying nozzle effect, the particles in the nozzle area were pushed away by the atomised air, resulting in low density in that region.

The above test results indicate that ECT can be used in large-scale gas-solids fluidised beds to monitor the gassolids flow hydrodynamic behaviour and provide useful information, e.g. monitoring the performance of spraying 
nozzle, for process control. However, sensor construction is a key issue to commercial success of ECT to be applied to fluidised beds of produce scale.

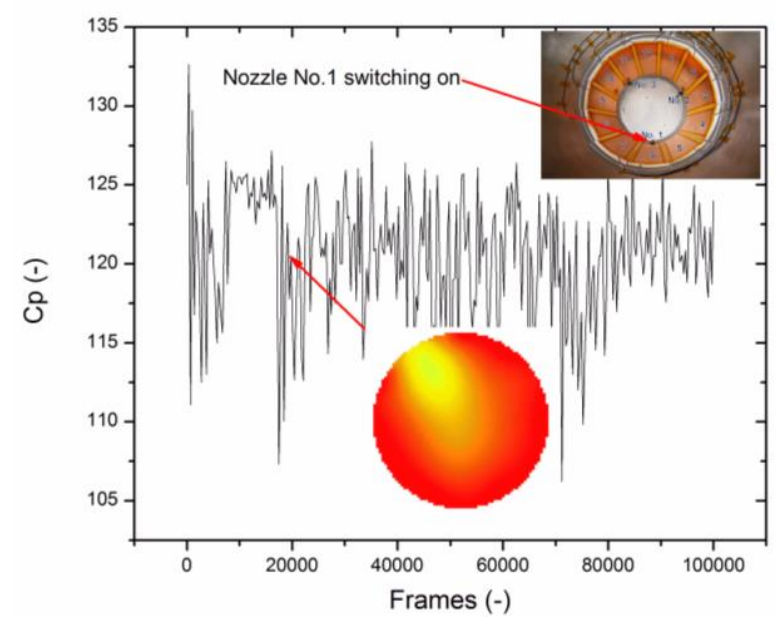

(a) One nozzle switching on

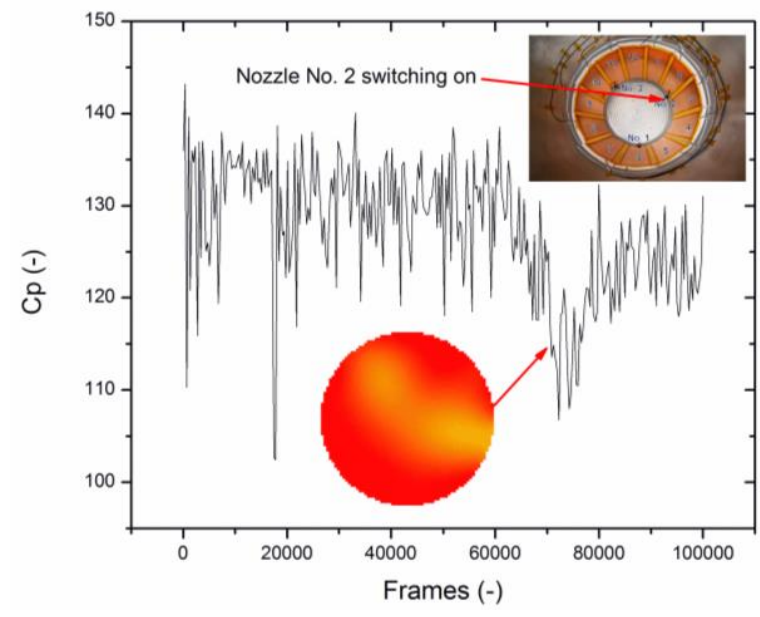

(b) Two nozzles switching on

Figure 8 Test results with FlexStream ${ }^{\mathrm{TM}}$ and atomised air nozzle

\subsection{Flow regimes identification by ECT}

The flow regime, e.g. bubbling, slugging and circulating, plays an important role on the mass and heat transfer in gas-solids fluidised beds. It may be identified by frequency spectrum of measured parameters, such as from pressure and capacitance signals. Frequency domain analysis based on Fast Fourier Transformation (FFT) is a common tool to investigate fluctuation of time series signals in gas-solids fluidised beds. To analyse the information obtained by ECT in time series, FFT is used to analyse the flow characteristics.

Figure 9 (a) shows the reconstructed images and the frequency spectrum with different flow regime for the labscale fluidised bed as shown in Figure 2 (b). The images show the change in solids concentration with different flow rate. The frequency spectrum obtained by FFT illustrates a peak corresponding to about $1.5 \mathrm{~Hz}$ for bubbling fluidisation, and between $1.2 \mathrm{~Hz}$ and $2.0 \mathrm{~Hz}$ for slugging fluidisation. For the circulating flow regime, the frequency spectrum is more irregular than those in bubbling and slugging fluidisation. The peak occurs mostly below $1.5 \mathrm{~Hz}$ with the highest peak at $1.25 \mathrm{~Hz}$. This feature reflects the chaotic flow pattern in the turbulent flow regime. The above results agree well with the pressure fluctuation measurement in the bottom of the bed, which gives a domain frequency between 0.5 and $1.4 \mathrm{~Hz}$ (Svensson et al. 1996). Figure 9 (b) shows the frequency spectrum for different-scale fluidised bed with the same flow regime, i.e. circulating. For all three scales, the domain frequency is less than $1.5 \mathrm{~Hz}$. For the pilot- and production-scale fluidised beds, they nearly have the same spectrum distribution. However, the spectrum for the lab-scale one is slightly complex than that in the pilot- and production-scale. The main reason can be the effect of the sensitivity distribution. For the labscale sensor, the measurement is sensitive to the gas-solids flow all over the cross section. However, the measurement is less sensitive to the change in the central region in the pilot- and production-scale. Therefore, frequency spectrum only contains the information from the region near wall for the pilot- and production-scales.

\subsection{ECT sensor with combined electrodes for dynamics test in a Wurster fluidised bed}

The gas-solids flow in a Wurster fluidised bed used in the pharmaceutical industry can be divided into four regions, which depend on each other, covered by particles in circulation (Teunou and Poncelet 2002), as shown in Figure 10 from CFD simulation. The central region is the spouting zone (1), where particles are sucked by an air flow to the entry of the insert cylinder. Particles are wetted in this region by spraying coating liquid. In the inner cylinder zone (2), particles are transported as pneumatic conveying. The drying process takes place in this region. In the annular zone (3), particles are falling down towards the bottom of the fluidising chamber. In the tampon zone (4), particles are moving slowly in successive jumps towards the spouting zone. To achieve proper coating, wet particles must be dried during their ascent in the Wurster tube. The mean drying time should be shorter than the time necessary for a particle to travel along the Wurster tube. Therefore, it is necessary to mount some electrodes inside the inner tube to obtain solids distribution. 

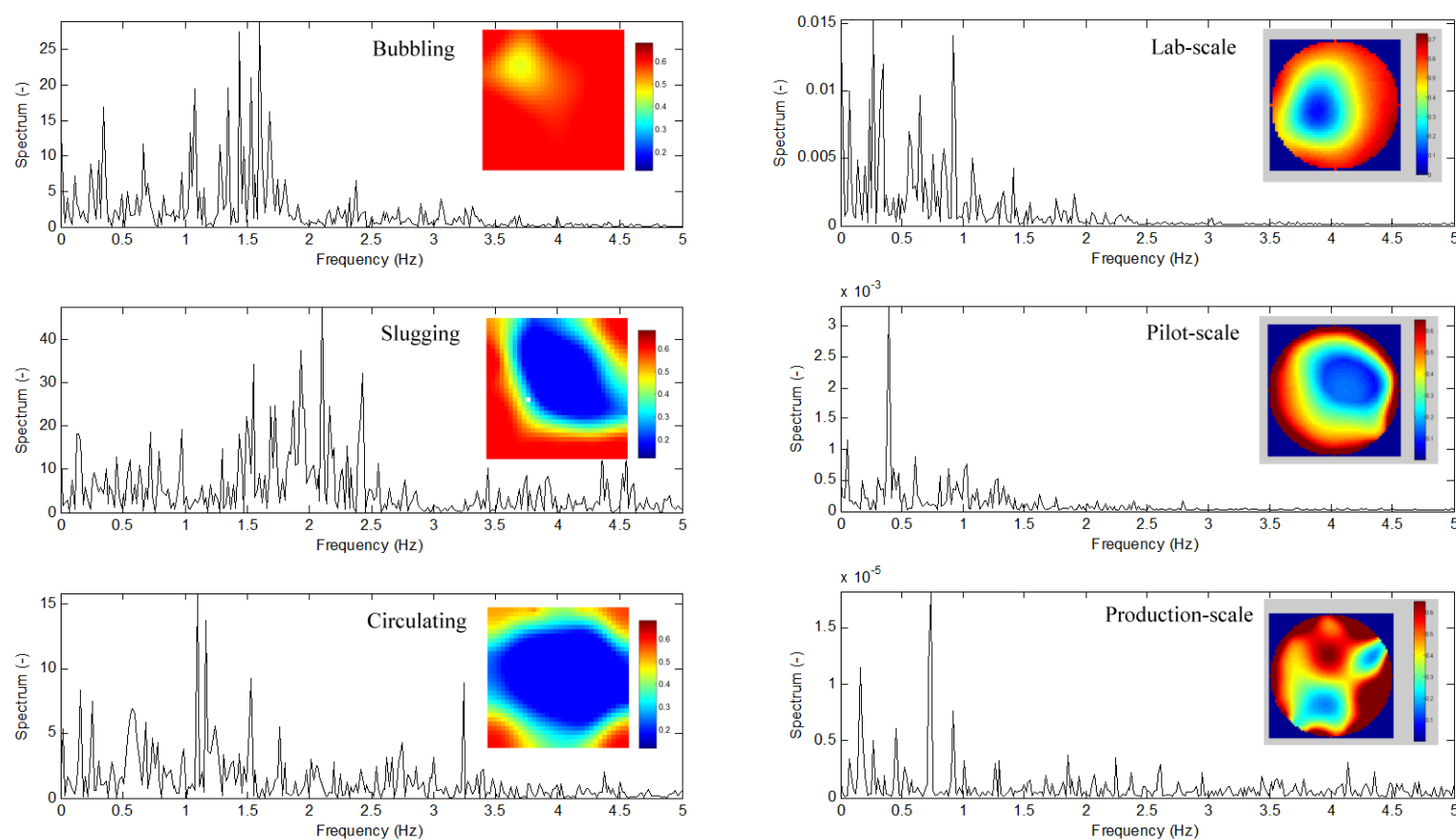

(a) Different flow regime

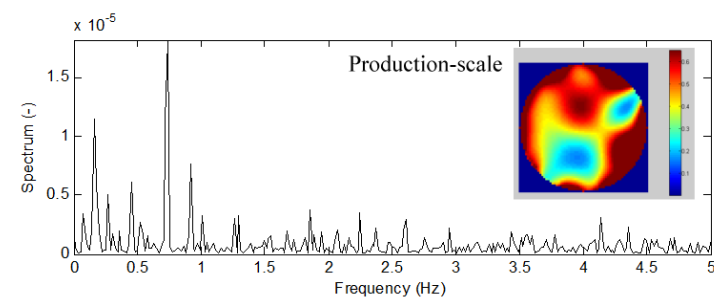

(b) Different scale

Figure 9 Frequency spectrum distributions for different flow regime and different scale

Solids

concentration

in $\mathrm{X}-\mathrm{Z}$ plane

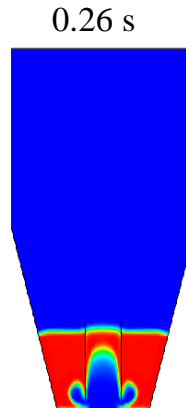

$0.66 \mathrm{~s}$
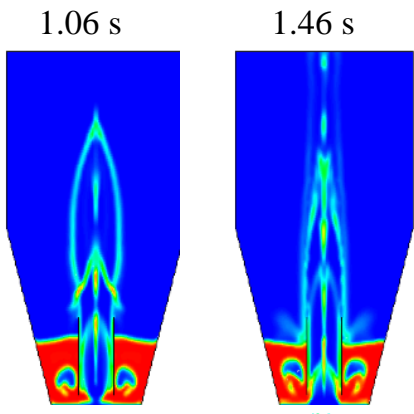

Solids

velocity

in $\mathrm{X}-\mathrm{z}$ plane
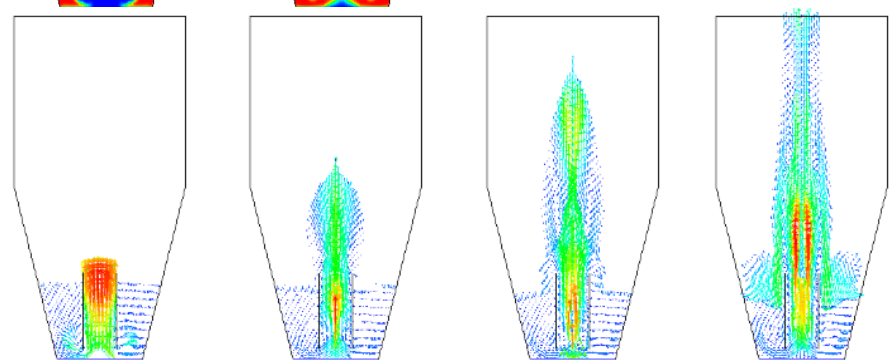

(a) Particle velocity and concentration

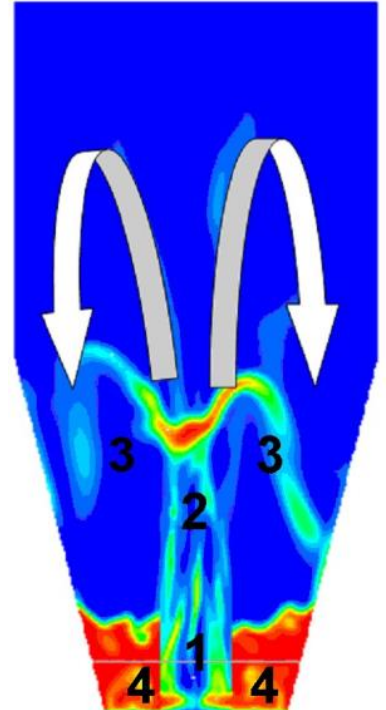

(b) Flow regimes

Figure 10 CFD simulation results (scale: $25 \mathrm{~cm}$ )

Figure 11 shows the solids distribution with different fluidisation velocity during a coating process, which was measured by three ECT sensors: (1) conventional ECT sensor, (2) 12-4 combined sensor and (3) 12-4-8 combined sensor. It is difficult to see the change in concentration with fluidisation velocity, and difficult to see the solids distribution inside the inner tube by the conventional 12-electrode sensor. As indicated by the CFD simulation results as shown in Figure 11, some particles are sucked to the inner tube from the bottom and move upward in the tube. The concentration in this region is very low, compared with the annular region. The measurement results with 12-4-8 combined electrodes clearly show the gas-solids flow behaviour in the annular region. Compared those images, the advantage of 12-4-8 combined ECT sensor can be seen in monitoring and controlling the fluidised bed coating process. 
12

electrodes

sensor

12-4

electrodes

sensor

$12-4-8$

electrodes

sensor
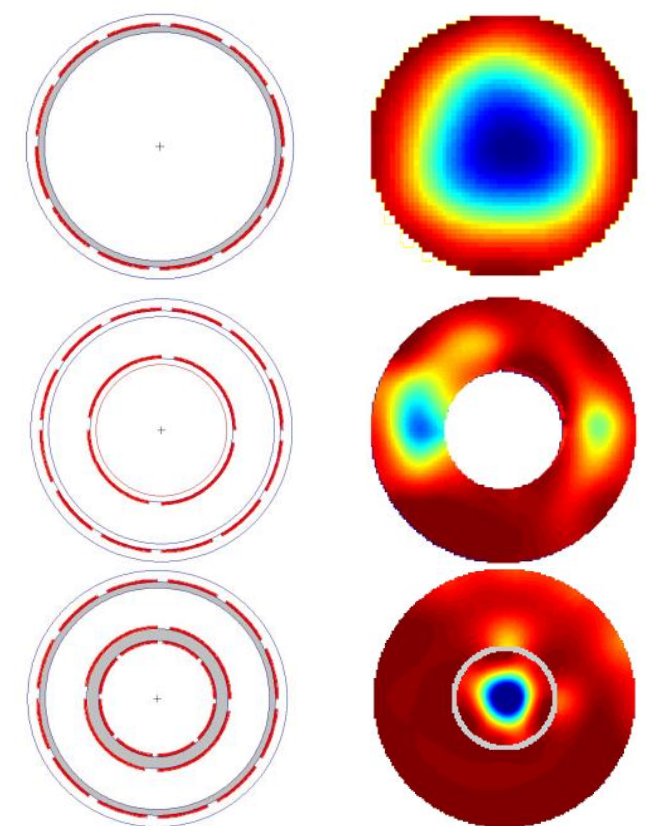

(a) $0.5 \mathrm{~m} / \mathrm{s}$
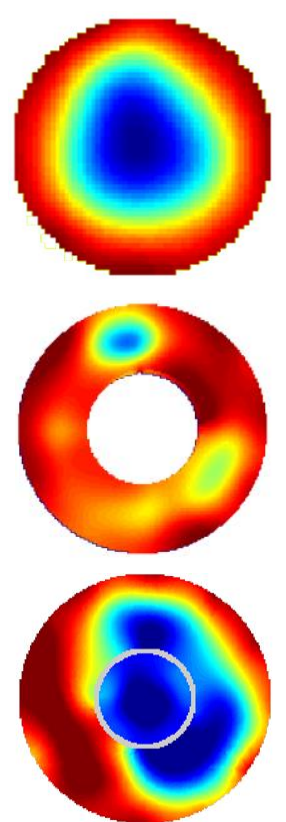

(b) $2.0 \mathrm{~m} / \mathrm{s}$
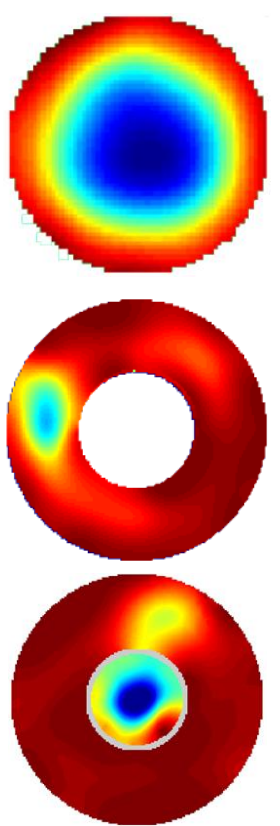

(c) $3.0 \mathrm{~m} / \mathrm{s}$

Figure 11 ECT measurement results

To apply the 12-4-8 electrode sensor in real industry environment, there are a few key issues for the sensor design and measurement strategy: (1) Due to the metal wall of fluidised beds, an ECT sensor has to be placed onto the inner wall of a product chamber. The ECT electrodes must be fixed firmly and should not contact with process materials to avoid contamination. (2) Due to the increase in diameter, the 3D effect of electric field becomes serious. The size of electrodes must be optimised (Yang et al. 1999, Peng et al. 2005). (3) The ECT sensor cables with a production-scale fluidised bed of large diameter are longer than with small-scale fluidised beds, resulting in larger stray capacitance (Yang et al. 2003). The cables should be as short as possible to reduce the stray capacitance. The cables should be fixed inside a fluidised bed in such a way that the disturbance of cables on the flow inside of the fluidised bed is kept being minimum. (4) Due to large electrodes and long cables, the stray capacitance, including capacitance of cables and capacitance between the electrodes and shielding, is much larger than small-scale fluidised beds. An optimized excitation frequency and voltage should be used to reduce the effect of large stray capacitance (Yang et al. 2003).

The unique features of Wurster fluidised beds are that they have excellent mixing capacity and spraying coating efficiency, but they are highly dependent on the quality of bubble characteristics in the annular zone and particle-droplet interaction in the coating zone, which to large extent depend on the distributor design and gap setting. To understand the fluidisation hydrodynamics of a Wurster fluidised bed, it is essential to assess how airflow is distributed. The above ECT measurement results show that ECT with combined electrode sensors can improve the understanding. This is the first time that ECT was used to synchronously visualise both inside and outside of Wurster tube, i.e. coating zone and annulus zone, to understand the gas-solids flow characteristics.

\subsection{Dynamic MWT measurement in gas-solids fluidised beds for spraying coating}

Due to spray coating solvent into the bed, the gas-solids flow in a fluidised bed drying process is more complex than conventional fluidisation process. Typically, the moisture content of particles in a fluidised bed drying process is between $1 \%$ and $25 \%$ (Wang et al., 2016), and the particle permittivity and conductivity can change dramatically in the whole process due to the change in moisture (Turton 2008). In such condition, ECT has some limitation (Wang et al. 2016). One possibility is to use MWT to measure the complex process. Therefore, an MWT sensor with 16 symmetrically arranged antennas as shown in Figure 3 was installed on a gas-solids fluidised bed of $16 \mathrm{~cm}$ in diameter. The reference materials used for the low and high calibration are air and pellets with moisture content of $30 \%$ respectively. The normalised microwave signals are used to reconstruct the permittivity distribution by improved Newton-Kantorovich algorithm (Wu and Wang 2017).

Figure 12 shows the dynamic measurement in a fluidised bed drying process with different fluidisation velocity by MWT. In this measurement, the data acquisition speed is 31 frames per second, lower than ECT which is 100 
frames per second for 12 electrodes sensors. In term of spatial resolution, MWT is similar to ECT. However, the advantage is that MWT is that it works with a gas-solids process containing materials of high conductivity and hence wide moisture content range (Wang et al. 2016).

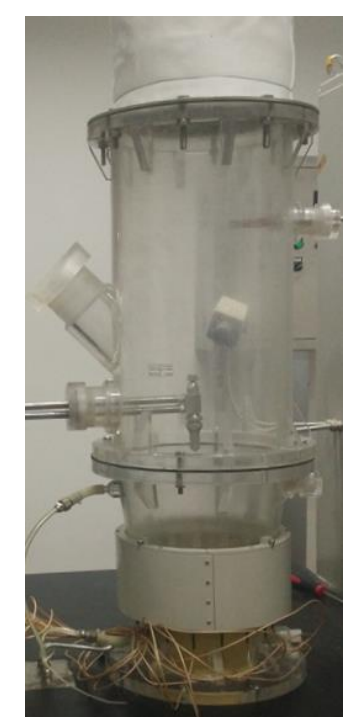

Fluidised bed with MWT sensor
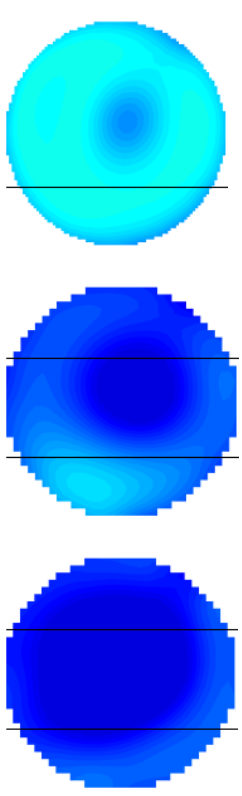

(a) $15 \mathrm{~min}$
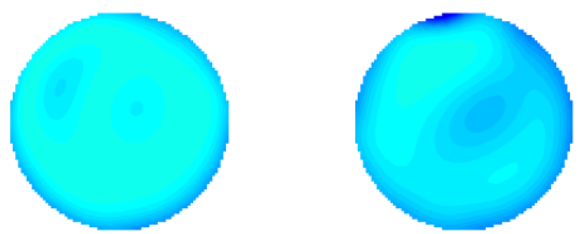

Case 1: V=1.16 m/s

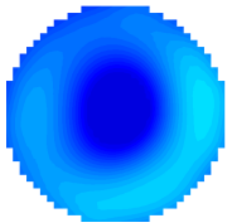

Case 2: $\mathrm{V}=1.74 \mathrm{~m} / \mathrm{s}$

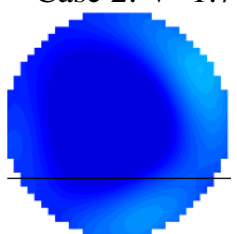

Case 3: $\mathrm{V}=3.0 \mathrm{~m} / \mathrm{s}$

(b) $20 \mathrm{~min}$
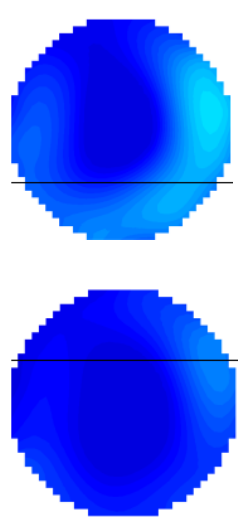

(c) $25 \mathrm{~min}$

Figure 12 Dynamic measurements in a fluidised bed drying process by MWT

To compare the performance of MWT and ECT for application in wetting and drying process with high moisture content, both MWT and ECT are used in a fluidised bed with moisture change. The measurement results of the wetting-drying processes using ECT and MWT are shown in Figure 13, including variation in both normalised permittivity $\left(\varepsilon_{\mathrm{N}}\right)$ and solids moisture content of particles. The moisture content is measured by taking samples using loss on drying (LOD) method. As can be seen, MWT shows the ability to measure the solids distribution with a wide range of moisture content, i.e. $0 \sim 35 \%$. The variation in the normalised permittivity has the same tendency with the moisture content. However, the normalised permittivity measured by ECT has a sharp decrease when the moisture content of particles increased up to 20\%, and ECT images are obviously blurred in the time period of 60 and $80 \mathrm{~min}$. The result indicates that ECT has limitations in measurement of high moisture content.

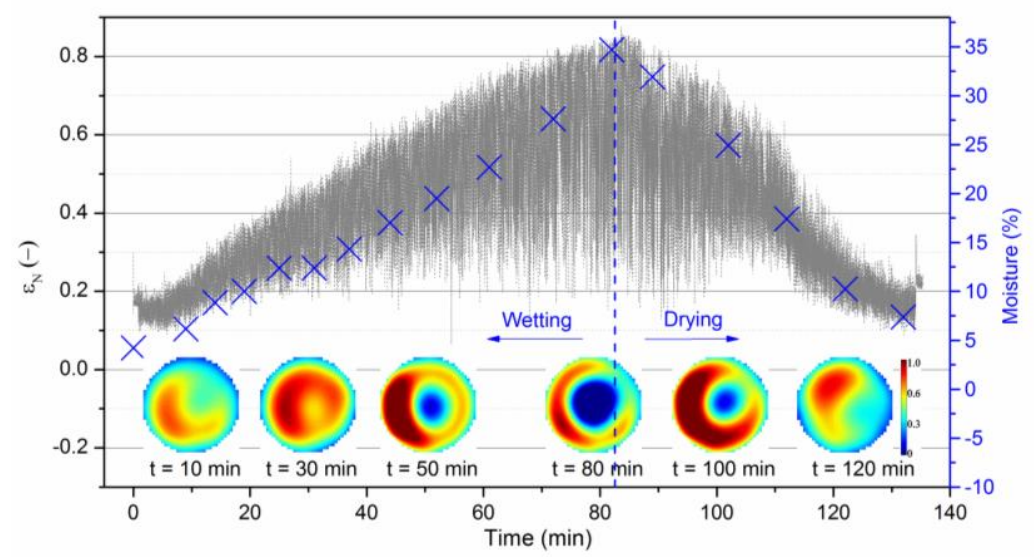

(a) MWT result 


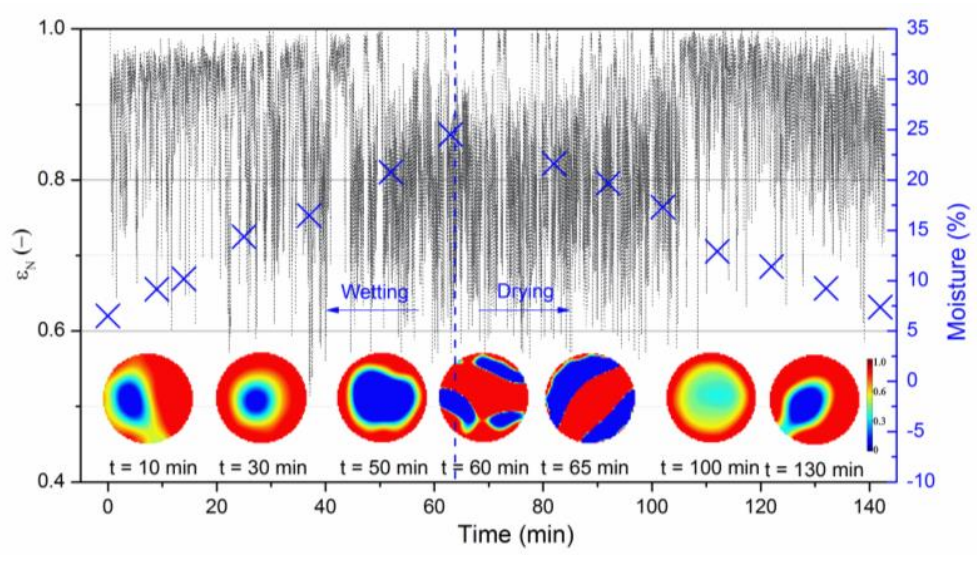

(b) ECT result

Figure 13 Comparison of MWT and ECT for dynamic measurement in fluidised bed wetting-drying process

\subsection{Sensitivity analysis}

To evaluate the performance of ECT and MWT and to investigate the effects of sensor structure and dimension on image quality, normalised sensitivity coefficient, $\mathrm{K}$, is introduced, which describes the relative change in output variable $\sigma$ as a result of a relative change in input variable $\varpi$ (Ronsse et al. 2009). In this research, the input variables for ECT are the sensor diameter, the exciation frequency and voltage respectively. For MWT, the input variables are the sensor diamter and excitation frequency respectively. The detailed values are given in Table 3.The output varialbe is SNR both for ECT and MWT. The normalised senstivity coefficienty is defind as

$$
\mathrm{K}=\frac{\partial \sigma}{\sigma} \cdot \frac{\varpi}{\partial \varpi}
$$

SNR is defined as (Hu and Yang 2006)

$$
\mathrm{SNR}=20 \log _{10}\left(\frac{\text { Signal }}{\text { Noise }}\right)=20 \log _{10} \sqrt{\frac{\sum_{\mathrm{i}=1}^{\mathrm{M}} \mathrm{C}_{\mathrm{i}}^{2}}{\sum_{\mathrm{i}=1}^{\mathrm{M}}\left(\mathrm{C}_{\mathrm{i}}-\overline{\mathrm{C}}\right)^{2}}}
$$

where, $\mathrm{C}_{\mathrm{i}}$ is measured capacitance, $\overline{\mathrm{C}}$ is average of measured capacitance, and $\mathrm{M}$ is the total number of measurement frames.

Table 3 Input variables for ECT and MWT

\begin{tabular}{lll}
\hline Input variable & ECT & MWT \\
\hline Dimension $(\mathrm{cm})$ & $10,50,100$ & $8,16,20$ \\
Frequency $(\mathrm{kHz}$ for ECT, GHz for MWT) & $100,200,300,400$ & $1.0,1.3,1.6,1.92 .2,2.5$ \\
Voltage $\left(\mathrm{V}_{\mathrm{p}-\mathrm{p}}\right)$ & $12,15,17,20$ & - \\
\hline
\end{tabular}

Figure 14 shows the normalised sensitivity coefficient for ECT and MWT. It is clear that the ECT is more sensitivity to the changes in diameter and frequency. It is less sensitive to the voltage. Therefore, for an industrial application of ECT, both the sensor dimension and excitation frequency should be carefully considered. Compared with ECT, MWT is less sensitive to the diameter and frequency. Most of the coefficients fall within the range of \pm 0.3 . 


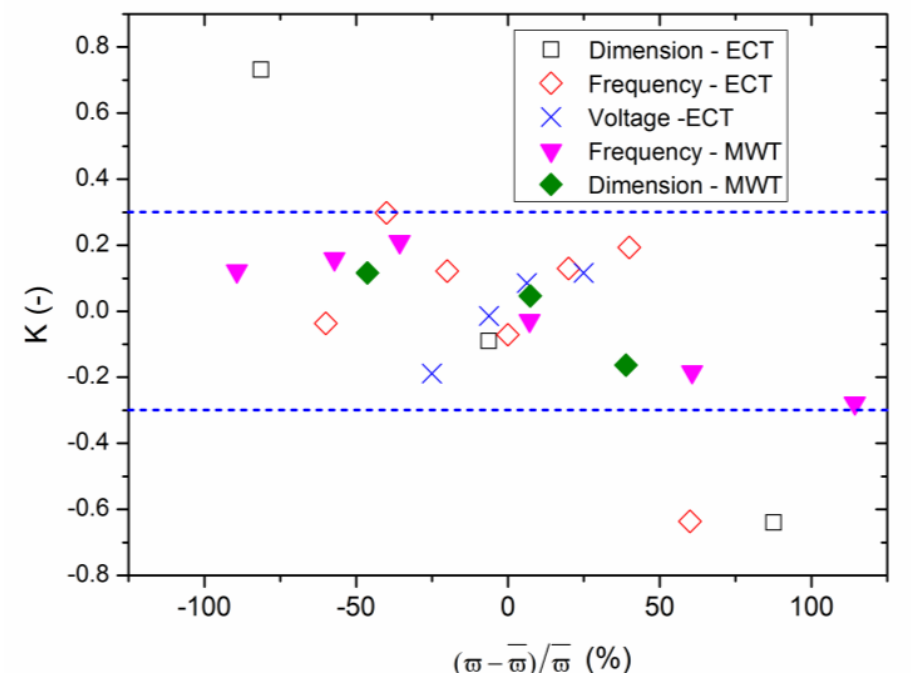

Figure 14 Sensitivity analyses for ECT and MWT

\section{Conclusions}

This paper is about application of ECT and MWT in gas-solids fluidised beds of different scale and structure. Part of the measurement results are compared and verified by available CFD simulation results. The work demonstrates that process tomography has been successfully applied in gas-solid fluidised beds with different scale and structure. The main conclusions are as follows.

- ECT can be used as an online tool to measure the change in solids distribution from lab-scale to production-scale fluidised beds, and for online flow regime identification. With the large scale rectangular ECT sensor, it is possible to control the operation parameters to avoid defluidisation, which would reduce the chance of hazard in industry.

- Properly sensor design is the key to achieve high quality signals. SNR is strongly related with optimised design of tomography sensors.

- Sensitivity analysis indicates that ECT is more sensitive to the sensor dimension and excitation frequency. For different structure and dimension of ECT sensors, variables need to be optimised for application in real industrial gas-solids process. Compared with ECT, MWT is less sensitive to the diameter and frequency.

- Compared with ECT, MWT can be used in the fluidised bed process with high moisture content, especially in the particles coating, drying and granulation process in the pharmaceutical industry. However, MWT has lower temporal resolution compared with ECT, i.e. 31 frames per second. For MWT, the key is to improve the temporal resolution to meet the high flow dynamics, which can possibly be made using high-speed PC cluster and GPU cards.

\section{Acknowledgements}

The authors would like to thank the National Natural Science Foundation of China (No. 61320106004 and 61771455), the Royal Society Newton Advanced Fellowship (NA170124) and the international exchange scheme between NSFC and Royal Society of United Kingdom and CAS Interdisciplinary Innovation Team for supporting this work. The authors would also like to thank the GEA Pharma Systems Ltd in Bubendorf (Switzerland) for providing FlexStream ${ }^{\mathrm{TM}}$ fluidised bed for experiment.

\section{References}

Agu C.E., Tokheim L.A., Eikeland M.E. and Moldestad B.M.E. (2017), Determination of onset of bubbling and slugging in a fluidized bed using a dual-plane electrical capactiance tomography system, Chem. Eng. J., 328, pp 997-1008.

Andrews M.J. and $\mathrm{O}^{\prime}$ Rourke P.J. (1996), The multiphase particle-in-cell (MP-PIC) method for dense particulate flows, Int. J. Multiphase Flow, 22, pp 379-402.

Banaei M., van Sint Annaland M., Kuipers J.A.M. and Deen N.G. (2015), On the accuracy of Landweber and Tikhonov reconstruciton techniques in gas-solid fluidized bed applications, AIChE J., 61, pp 4102-4113. 
Cao Z., Xu L., Fan W. and Wang H. (2010), Electrical capacitance tomography with a non-circular sensor using the dbar method, Meas. Sci. Technol., 21, pp 15502-15506.

Chandrasekera T.C., Li Y., Moody D., Schnellmann M.A., Dennis J.S. and Holland D.J. (2015), Measurment of bubble sizes in fluidised beds using electrical capacitance tomography, Chem. Eng. Sci., 126, pp 679-687.

Depypere F., Pieters J.G. and Dewettinck K. (2004), CFD analysis of air distirbution in fluidised bed equipment, Powder Technol., 145, pp 176-189.

Ding J. and Gidaspow D. (1990), A bubbling fluidisation model using kinetic theory of granular flow, AIChE J., 36, pp 523-538.

Du B., Warsito W. and Fan L.S. (2005), ECT studies of gas-solid fluidised beds of different diameters, Ind. Eng. Chem. Res., 44, pp 5020-5030.

Dyakowski T., Jeanmeure L.F.C. and Jaworski A.J. (2000), Applications of electrical tomography for gas-solids and liquid-solids flows - a review, Powder Technol., 112, pp 174-192.

Fayed M. and Otten L. (2013), Handbook of powder science \& technology, Springer Science \& Business Media 2013, pp 97-102.

Francesco S., Giancarlo P. and Svein E. (2009), A preparatory study on subsurface exploration on Mars using GPR and microwave tomography, Planetary and Space Science, 57, pp 1076-1084.

Franchois A. and Pichot C. (1997), Microwave imaging - Complex permittivity reconstruciton with a Levenberg - Marquardt method, IEEE Trans. on Antennas and Propagation, 45, pp 203-215.

Franchois A. and Tijhuis A.G. (2003), A quasi-Newton reconstruction algorithm for a complex microwave imaging scanner environment, Radio Science, 38, pp 8011-8023.

Geldart D. and Baeyens J. (1985), The design of distributors for gas-fluidized beds, Powder Technol., 42, pp 6778.

Ge R.H., Ye J.M., Wang H.G. and Yang W.Q. (2014), Measurement of particle concentration in a Wurster fluidised bed by electrical capacitance tomography sensors, AIChE J., 60, pp 4051-4064.

Ge R.H, Ye J.M., Wang H.G. and Yang W.Q. (2016), Investigation of gas-solids flow characteristics in a conical fluidised bed dryer by pressure fluctuation and electrical capacitance tomography, Drying Technol., 34, pp 1359-1372.

Harada H., Wall D. J. N., Takenaka T. and Tanaka M. (1995), Conjugate gradient method applied to inverse scattering problem, IEEE Trans.actions on Antennas and Propagation, 43, pp784 -792.

Hu X.H. and Yang W.Q. (2006), Design of a data acquisition and function generation unit with USB, Meas. Sci. Technol., 17, N17-N23.

Hu J., Wu Z., McCann H., Davis L.E. and Xie C.G. (2005), Sequential quadratic programming method for solution of electromagnetic inverse problems, IEEE Trans. Antennas and Propagation, 53, pp 2680-2687.

Jiang Y., Qiu G.Z. and Wang H.G. (2014), Modelling and experimental investigation of the full-loop gas-solid flow in a circulating fluidised bed with six cyclone separators, Chem. Eng. Sci., 109, pp 85-97.

Joachimowicz N., Pichot C. and Hugonin J.P. (1991), Inverse scattering: an iterative numerical method for electromagnetic imaging, IEEE Trans. on Antennas and Propagation, 39, pp1742-1752.

Koornneef J., Junginger M. and Faaij A. (2007), Development of fluidised bed combustion - An overview of trends, performance and cost, Progress in Energy and Combustion Science, 33, pp 19-55.

Li X.X., Jaworski A.J. and Mao X.A. (2017), Comparative study of two non-intrusive measurment methods for bubbling gas-solids fluidized beds: Electrical capacitance tomography and pressure fluctuations, Flow Meas. Instrum., 2017 (in press).

Liu S., Wang H.G., Jiang F. and Yang W.Q., (2002), A new image reconstruction method for tomography investigation of fluidized beds, AIChE J., 48, pp 1631-1638.

Liu S., Fu L., Yang W.Q., Wang H.G. and Jiang F. (2004), Prior-online iteration for image reconstruction with electrical capacitance tomography, IEE Proc. - Sci. Meas. Technol., 151, pp 195-200

Liu S., Chen Q., Wang H.G., Jiang F., Yan R.S., Ismail I. and Yang W.Q. (2005), Electrical capacitance tomography for gas-solids flow measurement, Flow Meas. Instrum., Special Issue on Tomographic Techniques for Multiphase Flow Measurement, 16, pp 135-144.

Lobel P., Kleinman R.E., Pichot C. and Blanc-Feraud L. (1996), Conjugate-gradient method for solving inverse scattering with experimental data, IEEE Antennas and Propagation Magazine, 38, pp 48-51.

Lun C.K.K., Savage S.B., Jeffrey D.J. and Chepumiy N. (1984), Kinetic theories for granular flow: inelastic particles in coquette flow and slightly inelastic particles in a general flow field, J. of Fluid Mechanical, 140, pp 223-256.

Makkawi Y.T. and Wright P.C. (2004), Electrical capacitance tomogropahy for conventional fluidised bed measurment - remarks on the measuring technique, Powder Technol., 148, pp 142-157.

Marashdeh Q., Warsito W., Fan L.S. and Teixeira F.L. (2006), A nonlinear image reconstruction technique for ECT using a combined neural network approach, Meas. Sci. Technol., 17, pp 2097-2103.

Pain C.C., Mansoorzadeh S. and Oliverira C.R.E. (2001), A study of bubbling and slugging fluidised beds using the two-fluid granular temperature model, Int. J. Multiphase Flow, 27, pp 527-551. 
Peng L.H., Mou C.H., Yao D.Y. and Xiao D.Y. (2005), Determination of the optimal axial length of the electrode in an electrical capacitance tomogrpahy sensor, Flow Meas. Instrum., 16, pp 169-175.

Pugsly T., Tanfara H., Malcus S., Cui H., Chaouki J. and Winters C. (2003), Verification of fludiized bed electrical capacitance tomogrpahy measurment with a fibre optic probe, Chem. Eng. Sci., 58, pp 3923-3934.

Qiu G.Z., Ye J.M. and Wang H.G. (2015), Investigation of gas-solids flow characteristics in a circulating fluidized bed with annular combustion chamber by pressure measurements and CPFD simulation, Chem. Eng. Sci., 134, pp 433-447.

Roger A. (1981), A Newton Kantorovich algorithm applied to an electromagnetic inverse problem, IEEE Transactions on Antennas and Propagation, 29, pp 232-238.

Ronsse F., Pieters J.G. and Dewettinck K. (2009), Modeling heat and mass transfer in batch, top-spray fluidised bed coating processes, Powder Technol., 190, pp 170-175.

Rüdisüli M., Schildhauer T.J., Biollaz S.M.A. and van Ommen J.R. (2012), scale-up of bubbling fluidised bed reators - A review, Powder Technol., 217, pp 21-38.

Semenov S.Y., Bulyshev A.E., Abubakar A., Posukh V.G., Sizov Y.E, Souvorov A.E., van den berg P.M. and Williams T.C. (2005), Microwave-tomographic imaging of the high dielectric-contrast objects using different image-reconstruction approaches, IEEE Trans. on Microwave Theory and Techniques, 53, pp 22842294.

Svensson A., Johnsson F. and Leckner B. (1996), Fluidization regimes in nonslugging fluidized bed: Influence of pressure drop across the air distributions, Powder Technol., 86, pp 229-312.

Snider D.M. (2001), An incompressible three-dimensional multiphase particle-in-cell method for dense particle flows, Journal of Computational Physics, 170, pp 523-549.

Sun J.Y. and Yan Y. (2016), Non-intrusive measurment and hydrodynamics characterization of gas-solid fludiized beds: a review, Meas. Sci. Technol., 27, 112001.

Teunou E. and Poncelet D. (2002), Batch and continuous fluid bed coating - review and state of the art, J. of Food Eng., 53, pp 325-340.

Turton R. (2008), Challenges in the modelling and prediction of coating of pharmaceutical dosage forms, Powder Technol., 181, pp 186-194.

Van Ommen J.R. and Mudde R.F. (2008), Measurement the gas-solids distribution in fluidised beds - A review, Int. J. Chem. Reach. Eng., 6, pp 1-29.

Wang H.G. and Yang W.Q. (2010), Measurment of fluidised bed dryer by different frequency and different normalisation methods with electrical capcitance tomogrpahy, Powder Technol., 199, pp 60-69.

Wang H.G. and Yang W.Q. (2011), Scale up of an electrical capacitance tomography sensor for imaging pharmaceutical fluidised beds and validation by computational fluid dynamics, Meas. Sci. Technol., 22, 104015.

Wang H.G., Qiu G.Z., Ye J.M. and Yang, W.Q. (2016), Experimental study and modelling on gas-solids flows in a lab-scale fluidised bed with Wurster tube, Powder Technol., 300, pp 14-27.

Wang H.G., Zhang J.L., Ramili M.F., Mao M.X., Ye J.M., Yang W.Q. and Wu Z.P. (2016), Imaging wet granules with different flow patterns by electrical capacitance tomography and microwave tomography, Meas. Sci. Technol., 27, 114007.

Wang F., Marashdeh Q., Wang A. and Fan L.S. (2012), Electrcial capacitance volume tomography imagnig of three-dimensional flow structures and solids concentration distributions in a riser and a bend of gas solid circulating fludizied bed, Ind. \& Eng. Chem. Res., 51, pp 10968-10976.

Werther J. (1999), Measurement techniques in fluidised beds, Powder Technol., 102, pp 15-36.

Wu Z.P, McCann H., Davis L. E., Hu J., Fontes A. and Xie C.G. (2009), Microwave-tomography system for oiland gas-multiphase-flow imaging, Meas. Sci. Technol., 20, 104026.

Wu Z.P. (2015), Developing a microwave tomogrpahic system for multiphase flow imaging: advances and challenges, Trans. Institute of Measurment and Control, 37, pp 760-768.

Wu Z.P. and Wang H.G. (2017), Microwave tomogrpahy for industrial process imaging, IEEE Antennas and Propagation Magazine, 59, pp 61-71.

Xie C.G., Huang S.M., Hoyle B.S., Thorn R., Lenn C., Snowden D. and Beck M.S. (1992), Electrical capacitance tomography for flow imaging - system model for development of image reconstruction algorithms and design for primary sensors IEE Proc. G, 139, pp 89-98.

Xu L.J., Xu W.F., Cao Z., Liu X.B. and Hu J.H. (2014), Multiple parameters' estimation in horizontal well logging using a conductance-probe array, Flow Meas. Instrum., 40, pp 192-198.

Yan J., Lu X.F., Wang Q.H., Kang Y.H., L J.B., Zhou J.L., Zhang Y., Lv Z. and Sun S.C. (2017), Experimental and Numerical study on air flow uniformity in the isobaric windbox of a $600 \mathrm{MW}$ supercritial CFB boiler, Appled Thermal Engineering, 122, pp 311-321.

Yang W.Q., Spink D.M., York T.A. and McCann H. (1999), An image reconstruciton algorithm based on Labdweber's iteration mehtod for electrical capacitance tomogrpahy, Meas. Sci. Technol., 10, pp 1065-1069. 
Yang W.Q and Peng L.H. (2003), Image reconstruction algorithms for electrical capacitance tomography, Meas. Sci. Technol., 14, R1-R13.

Yang W.Q., Stott A.L. and Gamio J.C. (2003), Analysis of the effect of stray capacitance on AC-based capacitance tomography transducer, IEEE Trans. on Instrum. Meas., 52, pp 1674-1681.

Yang W.Q. (2010), Design of electrical capacitance tomogrpahy sensors, Meas. Sci. Technol., 21, 42001.

Zhang W.B., Wang C., Yang W.Q. and Wang C.H. (2014), Application of electrical capacitance tomography in particulate process measurement - A review, Advanced Powder Technol., 25, pp 174-188.

Zhao T., Nakamura Y., Liu K., Murata H. and Takei M. (2016), The effect of rolling amplitude and period on particle distribution behaviour in a rolling circulating fluidized bed, Powder Technol., 294, pp 484-492. 